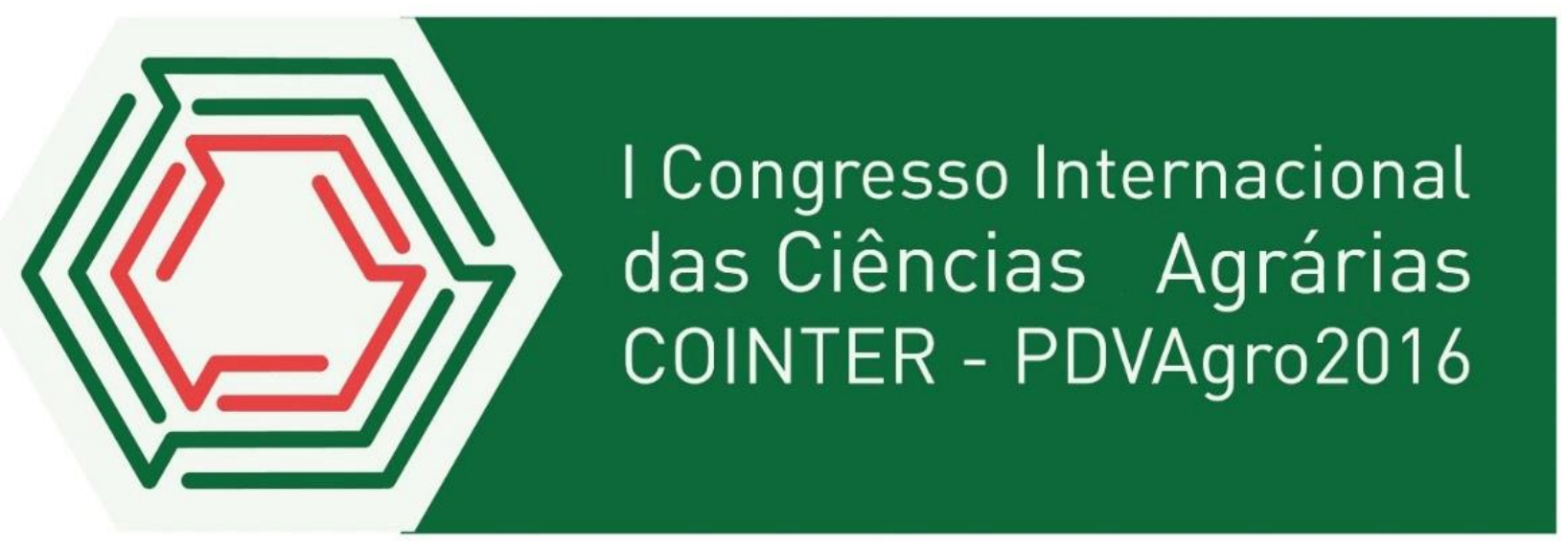

\title{
MEIO AMBIENTE NA PRÁTICA PEDAGÓGICA DO PROFESSOR DO ENSINO BÁSICO DO MUNICÍPIO DE BREJO DOS SANTOS-PB
}

\author{
Apresentação: Comunicação Oral
}

Israel Vieira Rocha ${ }^{1}$; Danilo Dantas da Silva ${ }^{1}$; Laiane Firmo de Lima ${ }^{1}$; Raquel Maria da Conceição ${ }^{1}$ Dalila Regina Mota de Melo $^{2}$

\begin{abstract}
Resumo
A Educação Ambiental é uma das ferramentas de orientação para a tomada de consciência dos indivíduos frente aos problemas ambientais. A escola como agente de mudanças na sociedade, tem grande influência na vida das pessoas e no que se diz respeito à preservação do meio ambiente, ela pode desenvolver projetos para melhorar e conscientizar seus alunos de que é preciso ter cuidado com o meio ambiente e investir em uma educação mais qualificada tanto para o discente quanto para o docente. Portanto, este trabalho teve como objetivo verificar como o tema meio ambiente vem sendo trabalhado pelos docentes do Ensino Fundamental II e Ensino Médio das escolas do município de Brejo dos Santos-PB. Para isso foi aplicado um formulário de oito questões a quinze professores das disciplinas de Português, Matemática, História, Geografia, Ciências e Biologia da Escola Municipal do Ensino Fundamental Arão Teodomiro de Sousa e Escola Estadual do Ensino Fundamental e Médio Diva Guedes de Araújo. Após a coleta de dados, as respostas dos professores entrevistados foram analisadas de forma individual e coletiva. Com a análise realizada, pode-se observar o tema Meio Ambiente está sendo aplicado nas escolas do município de Brejo dos SantosPB ainda de forma tímida, sendo que ainda existe muitas barreiras que precisam ser quebradas para este tema ser mais trabalhado neste município. Desta forma, será necessário investir mais em capacitação nesta área para que se possa obter uma educação mais qualificada proporcionando aos seus alunos um maior crescimento no aprendizado e respeito ao meio ambiente.
\end{abstract}

Palavras-Chave: meio ambiente, práticas de ensino, vivência escolar.

\section{Introdução}

$\mathrm{Na}$ atualidade o mundo tem demonstrado muita preocupação com o meio ambiente, tendo em vista que este assunto tem importância mundial, pois é problema de todos. E no meio educacional do ensino fundamental II e ensino médio como será que este tema vem sendo

\footnotetext{
1 Licenciatura Plena em Ciências Agrárias, Universidade Estadual da Paraíba, E-mail: rochaisrael@outlook.com; danilo20silva@hotmail.com; laianefirmo@gmail.com; raquel21maria@hotmail.com.

${ }^{2}$ Doutora em Fitotecnia, Universidade Federal Rural do Semiárido, E-mail: dalilaregina@hotmail.com.
} 
explorado? Como estão se portando as novas gerações em relação à natureza? O que se tem feito para sua preservação? Como as escolas tem se portado diante da atual degradação do meio ambiente? Seus profissionais estão comprometidos com a preservação do ambiente? São questões importantes que discutiremos neste trabalho.

Escolhemos como temática o meio ambiente, pois se trata de uma questão fundamental a ser trabalhada na prática pedagógica dos professores e que em muita das vezes é negligenciada na grande maioria dos educandários do nosso país. Isso ocorre por que muitos profissionais entendem que esse assunto não tem importância na sua disciplina e valoriza pouco este tema que é fundamental de se trabalhar nas escolas. A escola no atual contexto tem que repensar sua trajetória, como ela tem se portado diante disto e ver o que ela pode fazer para melhorar o aprendizado prático dos seus alunos sobre o meio ambiente. Observar se dentro de suas paredes tem-se respeitado o ambiente ou se ela está parada em relação a toda esta problemática existente no atual momento.

Diante de todas estas questões relatadas, este trabalho teve como objetivo verificar como o tema Meio Ambiente vem sendo trabalhado pelos docentes do ensino fundamental 11 e do ensino médio das escolas do município de Brejo dos Santos-PB.

\section{Fundamentação Teórica}

A prática pedagógica pode ser entendida como a percepção da ação do professor no espaço da sala de aula (GIMENO SACRISTÁN, 1999). Dentro das práticas pedagógicas do professor, o tema meio ambiente é uma exigência a ser trabalhado nas escolas de acordo com a lei de $\mathrm{n}^{\circ} 9.795$ de 27 de abril de 1999, no art.2 $2^{\circ}$ que diz "a educação ambiental é um componente essencial e permanente da educação nacional, devendo estar presente, de forma articulada, em todos os níveis e modalidades do processo educativo, em caráter formal e não-formal” (BRASIL 2001).

Portanto, a Escola é um espaço privilegiado para estabelecer conexões e informações, como uma das possibilidades para criar condições e alternativas que estimulem os alunos a terem concepções e posturas cidadãs, cientes de suas responsabilidades e, principalmente, perceberem-se como integrantes do meio ambiente. "A educação formal continua sendo um espaço importante para o desenvolvimento de valores e atitudes comprometidas com a sustentabilidade ecológica e social" (LIMA, 2004).

De acordo com Andrade e Cavalcante (2012), "a escola com "formadora" de cidadãos, precisa desenvolver na comunidade escolar; meios, métodos e estratégias que venham conscientizar os alunos quanto à preservação do meio ambiente, afim de que os mesmos possam aprender e colocá-los em pratica.” 
A escola deve ser o lugar onde desafios intelectuais possam ser vivenciados e não apenas verbalizados. Porém, é preciso que os professores estejam discutindo e refletindo as noções de meio ambiente e suas inter-relações no plano físico-natural, biológico e social, procurando a partir disso, entender como o educando se relaciona com seu meio (CAVALCANTI et al., 2012). Nesse contexto, os professores exercem um papel muito importante no processo de construção de conhecimento dos alunos, nas modificações dos valores e condutas acerca do meio ambiente, de forma crítica, responsável e contextualizada.

\section{Metodologia}

A pesquisa foi realizada no período de 25 de agosto a 11 de setembro de 2014, na Escola Municipal do Ensino Fundamental Arão Teodomiro de Sousa e na Escola Estadual de Ensino Fundamental e Médio Diva Guedes de Araújo, localizadas no município de Brejo dos Santos, Sertão Paraibano. A escolha dessas escolas se deu por serem as únicas de ensino fundamental II e ensino médio, dentre um total de onze (11) escolas públicas e uma (1) particular, distribuídas na zona rural e urbana do município.

Foi realizado um estudo de caso a partir da coleta de dados, do qual foi utilizado o método indutivo e como instrumento de pesquisa foi aplicado um formulário contendo oito perguntas, adaptadas de Cavalcante e Andrade (2012), das quais foram: Você possui alguma capacitação na área de meio ambiente? Você acha importante incluir os temas ambientais em sua prática pedagógica? O tema transversal meio ambiente vem sendo aplicado em sua pratica pedagógica? Qual (is) dos métodos pedagógicos abaixo citados você utiliza com mais frequência no desenvolvimento das aulas sobre meio ambiente no decorrer do ano letivo? a) dinâmicas, b) produção de documentos, c) peças teatrais, d) projetos pedagógicos, e) outros. Qual (is)? Na escola há desenvolvimento de projetos em cima do tema meio ambiente? Quais os temas relacionados a meio ambiente você aborda em sua disciplina? Você acha que é fácil aplicar na sua disciplina temas ambientais? e Quais as principais dificuldades que você enfrenta quanto a questão à aplicação de temas ambientais em sua sala de aula?

O formulário foi aplicado aos professores que responderam de forma livre. Participaram da pesquisa quinze professores que ministram as disciplinas Português, Matemática, Ciências, História, Geografia, e Biologia. Logo após a coleta de dados, as respostas dos professores entrevistados foram analisadas de forma individual e coletiva.

\section{Resultados e Discussão}


Diante dos resultados, observa-se que, em resposta à primeira pergunta vinte e três por cento (23\%) dos professores entrevistados disseram que possuíam capacitação na área de meio ambiente, porém ressaltaram que, essa capacitação era de poucas horas, sendo assim não era suficiente para trabalhar esse tema de tão grande abrangência com excelência. E a maioria (77\%) respondeu que não possuem capacitação na área (Gráfico 1). O que se torna mais um desafio para os docentes trabalharem este tema em sala de aula com seus alunos.

Gráfico 1 - Pergunta 1: Você possui alguma capacitação na área de meio ambiente? UEPB, Catolé do Rocha-PB, 2014. Fonte: Própria

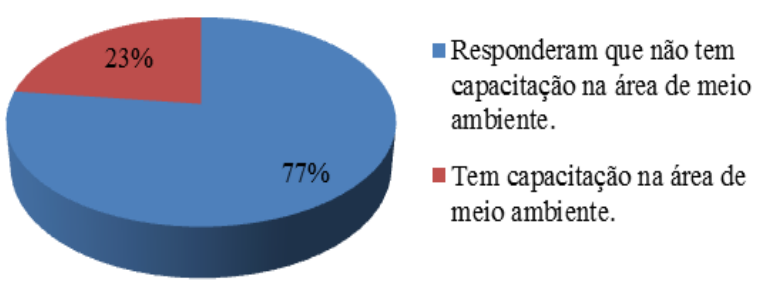

Diferente dos resultados encontrados por Andrade e Cavalcante (2012), em que apenas $11,11 \%$ dos profissionais tinham capacitação na área. Mostrando assim que se é necessário se investir muito na capacitação de profissionais para trabalhar temas de tão grande importância para a vida aqui na terra. E que profissionais capacitados vão trazer melhoramento na qualidade do ensino, proporcionando crescimento e amadurecimento quanto a questão ambiental em nossa vida.

Para a Secretaria de Educação Fundamental, capacitar em educação ambiental é levar o indivíduo a repensar a sua relação com o meio e assim permitir que haja mudanças atitudes em favor da melhoria da qualidade da vida na sociedade na qual o sujeito está inserido. Além disso, para professor de ensino fundamental é preciso que a capacitação lhe ofereça uma formação adequada e que estes docentes possam assim se sentir confiantes em modificar suas práticas de forma inovadora e incorpora a questão ambiental ao planejamento escolar (BRASIL, 2001).

De acordo com o gráfico 2, cem por cento (100\%) dos professores consideraram importante incluir temas ambientais em suas aulas, tendo em vista que, essa problemática da degradação do meio ambiente é responsabilidade de toda a humanidade e não deve ser limitada a apenas uma disciplina e que todas as disciplinas de maneira interdisciplinar deveria trabalhar essa temática.

Gráfico 2 - Pergunta 2: Você acha importante incluir os temas ambientais em sua prática pedagógica? UEPB, Catolé do Rocha-PB, 2014. Fonte: Própria 


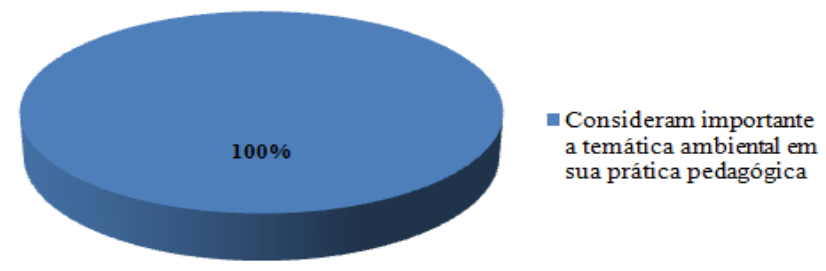

Observa-se no gráfico 3 que $77 \%$ dos professores já estão aplicando na sua prática pedagógica o tema meio ambiente e $23 \%$ responderam que não aplicam temas ambientais em suas práticas de ensino, pois é um tema difícil de ser abordado de forma interdisciplinar nos conteúdos das áreas de exatas, como foi enfatizado pelos professores da disciplina de matemática que responderam ao questionário. $\mathrm{O}$ que foi relatado na pergunta anterior, onde consideraram importante incluir temas ambientais em suas aulas, no entanto, tem dificuldades de aplicar o referido tema em suas disciplinas.

Gráfico 3 - Pergunta 3: O tema transversal meio ambiente vem sendo aplicado em sua pratica pedagógica? UEPB,

Catolé do Rocha-PB, 2014. Fonte: Própria
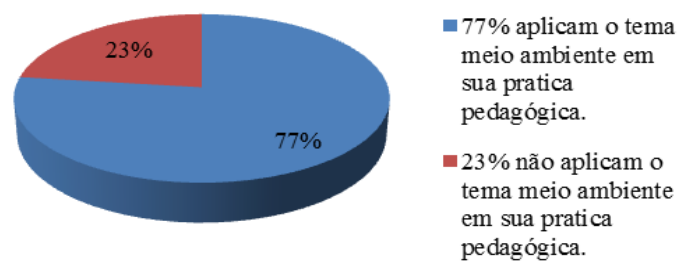

Para Ferreira et al. (2009), “a união da matemática com o meio ambiente precisa converterse num processo criativo, constituindo a porta de troca de produção dos comportamentos diários e da consciência dos valores culturais. Deve trabalhar situações que estejam presentes na vida cotidiana dos alunos e aplicando as condições a sua vida diária, e em que sentido aquilo vai estar presente em suas vidas."

No gráfico 4, observa-se que $47 \%$ dos professores utilizam os seguintes métodos pedagógicos; dinâmicas, gincanas culturais, oficinas e seminários, já $31 \%$ utilizam projetos pedagógicos, produção de documentos e debates sobre a temática, $16 \%$ utilizam peças teatrais e $6 \%$ não utilizam nenhum método mostrando desinteresse com o assunto.

Gráfico 04 - Pergunta 4: Qual (is) os métodos pedagógicos abaixo citado você utiliza com mais frequência no desenvolvimento das aulas sobre meio ambiente no decorrer do ano letivo? UEPB, Catolé do Rocha-PB, 2014. Fonte: 


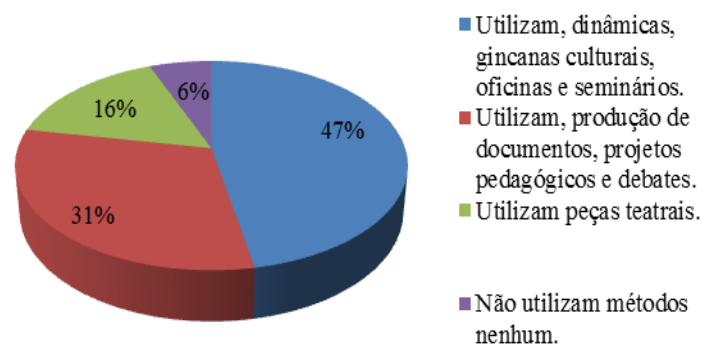

Com esta questão percebe-se que os professores entrevistados em sua maioria utilizam diversos métodos de ensino nas suas práticas pedagógicas. Isso mostra um "certo" avanço nas maneiras de se transmitir os conteúdos de forma mais atraente e eficaz na condução do conhecimento. Mostrando que apenas um percentual pequeno continua trabalhando na forma tradicional. Conforme Costa (2010), “o professor precisa planejar situações educativas que venham estimular a interação, oferecer acesso a novos elementos proporcionando informações concretas e consistentes". "A escola enquanto agente de transformação de conhecimentos, além de possibilitar a construção da cidadania plena desperta para a necessidade de consciência ambiental”, afirma Penteado (2003).

Como mostra o gráfico 5, sessenta e nove por cento (69\%) dos professores responderam que nas escolas onde eles trabalham não havia projetos voltados para o tema meio ambiente, enquanto que trinta e um por cento (31\%) responderam positivamente dizendo que nas suas escolas existem sim projetos voltados para esta temática, citando alguns desses projetos como, por exemplo, plantação de mudas e coleta seletiva. Reconhecendo que ainda é muito pouco e reafirmando que as escolas têm potencial para fazer muito mais e melhorar os que já existem.

Gráfico 5 - Pergunta 5: a escola há desenvolvimento de projetos em cima do tema meio ambiente? UEPB, Catolé do Rocha-PB, 2014. Fonte: Própria

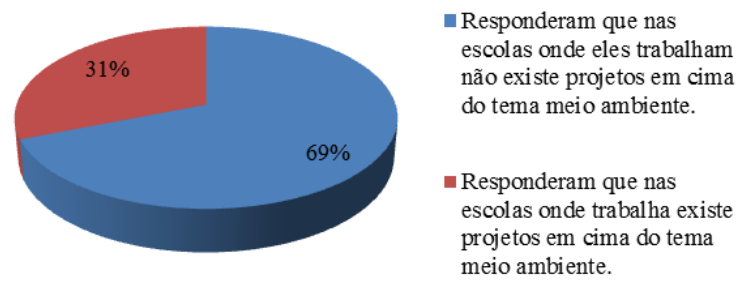

Como diz Legan (2004, p.10) “a educação escolar não deve só promover o conhecimento, mais incentivar habilidades e valores que orientarão e motivarão rumo a estilos de vida sustentáveis." A cidadania ambiental e a cultura de sustentabilidade serão necessariamente o 
resultado do fazer pedagógico que conjugue a aprendizagem a partir da vida cotidiana (GUTIÉRREZ; PRADO, 1999, p. 59).

De acordo com o gráfico 6, pode-se perceber que $38 \%$ dos professores entrevistados não responderam sobre a pergunta, pois existem vários assuntos relacionados com o meio ambiente. Já $31 \%$ responderam que abordam em suas aulas as seguintes temáticas; preservação do meio ambiente, desmatamento e reciclagem, temas estes muito bem relacionados com a temática e são temas bem presentes na realidade e de fácil compreensão; $15 \%$ dos professores responderam que trabalham os temas qualidade e economia da água, aquecimento global e efeito estufa que são hoje muito presentes em nossas vidas, pois já sentimos na pele a reação e maus cuidados que tiveram as gerações passadas e a presente com estes assuntos; $8 \%$ relataram que trabalham com os temas destino do lixo, coleta seletiva, extinção dos animais e desenvolvimento sustentável e $8 \%$ trabalham com espaços e dimensões em suas aulas.

Gráfico 6 - Pergunta 6: Quais os temas relacionados a meio ambiente você aborda em sua disciplina? UEPB, Catolé do Rocha-PB, 2014. Fonte: Própria

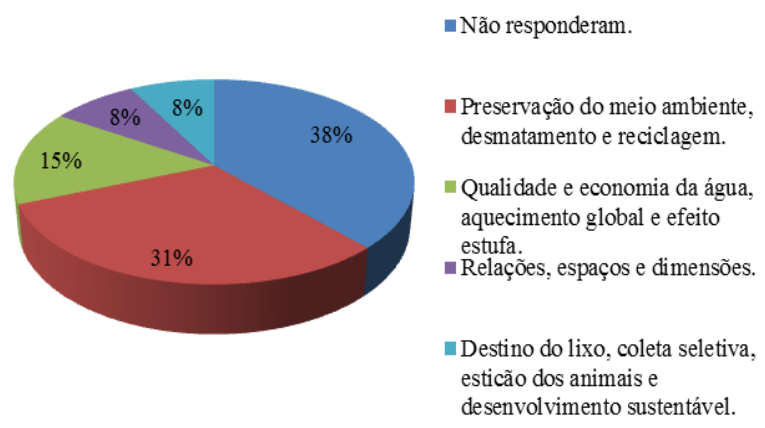

O gráfico 7 mostra que $69 \%$ dos professores entrevistados consideram fácil aplicar temas ambientais em suas disciplinas, mostrando que mais da metade destes profissionais de alguma forma estão trabalhando com a aplicação do tema em questão na sala de aula. Enquanto $23 \%$ não consideram fácil colocar esta temática nas suas disciplinas, considerando que as mesmas não têm muito em comum com os temas ambientais e $8 \%$ não responderam em relação a essa questão, preferindo não dar um posicionamento em relação a sua atuação com o tema em sala de aula.

Gráfico 7 - Pergunta 7: Você acha que é fácil aplicar na sua disciplina temas ambientais? UEPB, Catolé do Rocha-PB, 

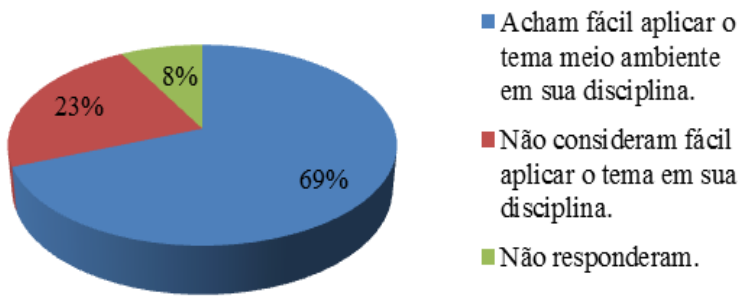

Mesmo na atualidade com muitas maneiras de abordar temas ambientais nas disciplinas, muitos professores ainda preferem continuar resistindo em abordar temas desta natureza nas suas aulas e preferem colocar obstáculos para não envolver temas ambientais nas suas aulas por motivos que tem justificativas poucos convincentes, pois existem muitas facilidades para se trabalhar com a interdisciplinaridade em todas as disciplinas sem perder o foco da disciplina que se leciona. Cabendo a cada profissional se atualizar com as temáticas que envolvem suas disciplinas. Contudo, estes mesmos profissionais que responderam que aplicam temas ambientais em suas disciplinas dizem ter algumas dificuldades. Como veremos na próxima questão.

Observa-se no gráfico 8 , que $39 \%$ dos professores entrevistados relataram que enfrentavam as seguintes dificuldades falta de recursos e desmotivação por parte dos alunos; já $31 \%$ colocaram que por sua disciplina não ser ciências, fica difícil abordar este tema, $15 \%$ relataram que falta muito apoio para colocar estes temas em aulas práticas e 15\% relataram não ter dificuldade alguma com este tema considerando muito fácil a sua aplicabilidade em sala de aula.

Gráfico 8 - Pergunta 8: Quais as principais dificuldades que você enfrenta quanto à questão à aplicação de temas ambientais em sua sala de aula? UEPB, Catolé do Rocha-PB, 2014. Fonte: Própria

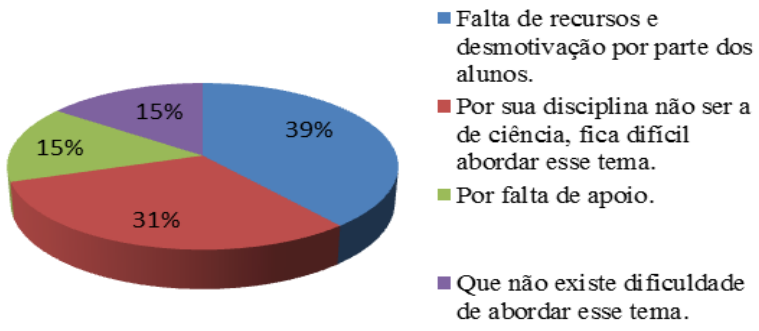

Aplicar temas ambientais em sala de aula sempre vai requerer um esforço de superação por parte dos professores. Como foi visto, a maioria dos docentes acham fácil aplicar temas ambientais em suas aulas, mesmo com falta de capacitação, o que mostra um esforço a mais por parte desses profissionais. No entanto, ainda existem outros, em menor número, que não consideram fácil aplicar essa temática em suas aulas, devido à falta de uma capacitação mais qualificada. 


\section{Conclusão}

O tema meio ambiente está sendo aplicado nas escolas do município de Brejo dos SantosPB ainda de forma tímida, sendo que ainda existe muitas barreiras que precisam ser quebradas para este tema ser mais trabalhado neste município. Desta forma, será necessário investir mais em capacitação nesta área para que se possa obter uma educação mais qualificada proporcionando aos seus alunos um maior crescimento no aprendizado e respeito ao meio ambiente.

\section{Referências}

ANDRADE, J. F.; CAVALCANTE, A. C. Educação Ambiental na Prática Pedagógica de Professores no Ensino Fundamental II. 2012. Monografia (Licenciatura plena em Ciências Biológicas) - Faculdade de formação de Professores de Garanhuns, Universidade de Pernambuco, Modalidade à Distância, Campina Grande, 2012.

BRASIL. Secretaria de Educação Fundamental. Panorama da Educação Ambiental no Ensino Fundamental. Brasília: MEC; SEF, p. 149, 2001.

CAVALCANTI, N. C. S.; SALES, R. P.; SANTOS, F. K. S. A prática pedagógica em educação ambiental crítica como mediadora de saberes. Revista de Ensino de Geografia. Uberlândia, v. 3, n. 5, p. 76-82, 2012.

COSTA, M. C. EDUCAÇÃO AMBIENTAL: da transversalidade à prática. p. 60, 2010. Monografia- UNIVERSIDADE ESTADUAL DA PARAÍBA, Nova Palmeira.

FERREIRA, D. H. L; LEITE, M. B. F; SCRICH, C. R. Explorando conteúdos matemáticos a partir de temas ambientais. VER. CIÊNCIA \& EDUCAÇÃO, Campinas, v. 15, nº.1, 2009. Disponível em: <http://www.scielo.br/pdf/ciedu/v15n1/v15n1ao8.pdf>. Acesso em: 10/ 09/2014.

GIMENO SACRISTÁN, J. Poderes instáveis em educação. Porto Alegre: ARTMED Sul, 1999.

GUTIERREZ, Francisco \& PARDO, Cruz. Ecopedagogia e cidadania planetária. São Paulo, SP: Cortez: Instituto Paulo Freire, Guia da Escola Cidadã, v. 1, 1999. 128 p.

LEGAN, L. Escola Sustentável: São Paulo/SP: Imprensa Oficial do Estado de São Paulo; Piranópolis: Instituto de permacultura e ecovilas do serrado, 2004. 172 p.

LIMA, W. Aprendizagem e classificação social: um desafio aos conceitos. Fórum crítico de Educação: Revista do ISEP/programa de mestrado em Ciências pedagógicas. 2004.

PENTEADO, H. D. Meio ambiente e formação de professores. 5. Ed. São Paulo: Cortez, p. 120, 2003. 